\section{PENGARUH KONSUMSI SERAT DENGAN PENGURANGAN RISIKO KANKER KOLON DI NEGARA BARAT: STUDI META ANALISIS}

Diterima 5 Juni 2018

Disetujui 30 Agustus 2018

Dipublikasikan 5 September 2018

\section{JKMA}

Jurnal Kesehatan Masyarakat Andalas diterbitkan oleh:

Program Studi S-1 Kesehatan Masyarakat Fakultas Kesehatan Masyarakat Universitas Andalas

p-ISSN 1978-3833

e-ISSN 2442-6725

12(2) $97-101$

@2018 JKMA

http://jurnal.fkm.unand.ac.id/index.php/jkma/

\title{
Masrul Masrul $^{1} \bowtie$
}

${ }^{1}$ Bagian Gizi, Fakultas Kedokteran, Universitas Andalas, Padang, Sumatra Barat, 25148

Abstrak

Pengaruh konsumsi diet dengan kanker kolorectal masih kontroversial. Penelitian dengan studi systematic review dan meta analisis dapat membuktikan kebenarannya. Penelitian ini bertujuan untuk mengetahui pengaruh konsumsi serat dengan pengurangan risiko kanker kolon di negara barat. Penelitian ini menggunakan studi meta-analisis berdasarkan artikel penelitian tentang konsumsi serat mengurangi risiko kanker kolorektal di negara-negara barat yang diterbitkan antara Januari 2000 dan Januari 2018 di database artikel online PubMed, ProQuest dan EBSCO. Odds rasio gabungan (POR) dihitung dengan fixed-effect model atau random effect model. Data disajikan dalam bentuk forest plots. Data dianalisis dengan menggunakan software Stata versi 14.2 (Stata Corporation). Penelitian ini mereview 405 artikel. Ada 7 penelitian yang dilakukan telaah sistematis dan dilanjutkan dengan Meta-analisis. Hasilnya menunjukkan konsumsi serat mengurangi risiko kanker kolorektal di negara-negara barat $(R R=0,83$ [95\% CI 0,75-0,93]). Hasil penelitian ini menyimpulkan konsumsi serat dapat mengurangi risiko kanker kolorektal di negara barat.

Kata Kunci: Kanker kolorektal, negara barat, serat

\section{FIBRE CONSUMPTION REDUCED RISK OF COLORECTAL CANCER PATIENTS IN WESTERN COUNTRIES: A META-ANALYSIS}

Abstract

\begin{abstract}
The association between dietary fibre and colorectal cancer risk is controversial. This systematic review and meta-analysis was performed to determine fibre consumption reduced risk of colorectal cancer patients in western countries. The authors conducted a meta-analysis of published research articles on fibre consumption reduced risk of colorectal cancer patients in western countries published between January 2000 and January 2018 in the online article databases of PubMed, ProQuest and EBSCO. Pooled relative risk (PRR) were calculated with fixed and random-effect models. Data were processed using Stata version 14.2 (Stata Corporation). This study reviewed 405 articles. There are 7 studies conducted a systematic review and continued with Meta-analysis. The results showed fibre consumption reduced risk of colorectal cancer patients in western countries $(R R=0.83$ [95\% CI 0.75-0.93]). This analysis confirmed fibre consumption reduced risk of colorectal cancer patients in western countries.
\end{abstract}

Keywords: Colorectal cancer, western countries, fibre

\section{$\bigotimes$ Korespondensi Penulis:}

Bagian Gizi, Fakultas Kedokteran, Universitas Andalas, Jl.Perintis Kemerdekaan, Padang, Sumatra Barat, 25127

Telepon/HP: 0751-31746, Email : masrulmuchtar@med.unand.ac.id 


\section{Pendahuluan}

Kanker yang dimulai dari usus besar atau rektum disebut dengan kanker kolorektal. Penyakit ini termasuk salah satu penyakit yang ganas dan sering terjadi di dunia yang menjadi peringkat ketiga di Amerika Serikat dan keempat di Asia sebagai penyakit yang terganas. ${ }^{(1,2)}$ Jumlah pengidap kanker kolorektal meningkat dengan cepat di berbagai negara bagian Barat menurut data World Health Organization (WHO). ${ }^{(3)}$

Berdasarkan faktor risiko kanker kolorektal dibedakan, menjadi faktor risiko yang dapat dimodifikasi dan tidak dapat dimodifikasi. Faktor risiko kanker kolorektal yang dapat dimodifikasi yaitu jarang melakukan aktivitas fisik, merokok, komsumsi minuman alkohol dalam periode yang lama, serta kurangnya makan makanan yang mengandung serat. Untuk faktor risiko kanker yang tidak dapat dimodifikasi yaitu genetika, usia, ras, riwayat keluarga, riwayat penyakit seperti tumor, dan kolitis ulserativa. (1,4,5) $^{-1}$

Diet adalah pilihan makanan yang biasa dimakan oleh seseorang. Diet diperkirakan memiliki efek 30 - 50\% terhadap angka kejadian kanker kolorektal yang terjadi di dunia. Salah satu faktor diet yang berkontribusi terhadap kanker kolorektal adalah konsumsi serat. Diet dengan makanan berserat berbanding terbalik dengan risiko kejadian kanker kolorektal. Tingginya serat makanan terbukti berpengaruh untuk mencegah risiko kanker kolorektal. ${ }^{(6,7)}$

Diet rendah serat dikaitkan dengan peningkatan risiko kanker kolorektal. ${ }^{(7)}$ Namun, karena variasi geografis yang luas, demografi pasien kanker kolorektal berbeda dari negara maju dan berkembang. Hal ini terjadi karena perubahan dalam pola diet dan gaya hidup sebagai akibat globalisasi dan peningkatan status ekonomi, serta ketersediaan program skrining yang dapat menentukan risiko kanker kolorektal.

Beberapa penelitian sebelumnya telah menunjukkan bahwa serat makanan dikaitkan dengan pengurangan risiko kanker kolorektal. ${ }^{(8-10)}$ Tetapi hasil lainnya tidak menemukan efek serat dalam penurunan risiko kanker kolorektal. ${ }^{(11,12)}$ Beberapa hasil penelitian ini menggambarkan tidak selalu konsistennya hasil yang didapatkan mengenai pengaruh serat terhadap kanker kolorektal. Oleh karena itu, penelitian ini bertujuan untuk mengetahui pengaruh konsumsi serat dengan pengurangan risiko kanker kolon di negara barat dengan beberapa penelitian melalui studi Meta-analisis sehingga kesimpulan yang diambil memiliki kekuatan yang lebih kuat. Hal ini penting untuk pencegahan risiko kanker kolorektal.

\section{Metode}

Penelitian ini menggunakan studi meta-analisis berdasarkan artikel penelitian tentang konsumsi serat mengurangi risiko kanker kolorektal di negara-negara barat yang diterbitkan antara Januari 2000 dan Januari 2018 di database artikel online PubMed, ProQuest dan EBSCO. Identifikasi artikel yang ditemukan, dilakukan dengan meninjau melalui judul artikel, dilanjutkan dengan meninjau abstrak, dan kemudian fulltext. Artikel dikeluarkan dari analisis jika: (a) hasil subjek tidak relevan, (b) bukan merupakan studi kasus-kontrol dan studi kohor (c) informasi yang diberikan dalam hasil penelitian tidak cukup untuk ekstraksi data. Risk rasio gabungan dihitung dengan fixed-effect model atau random effect model. Data disajikan dalam bentuk forest plots. Data dianalisis dengan menggunakan software Stata versi 14.2 (Stata Corporation).

\section{Gambar 1. Prosedur penelitian}

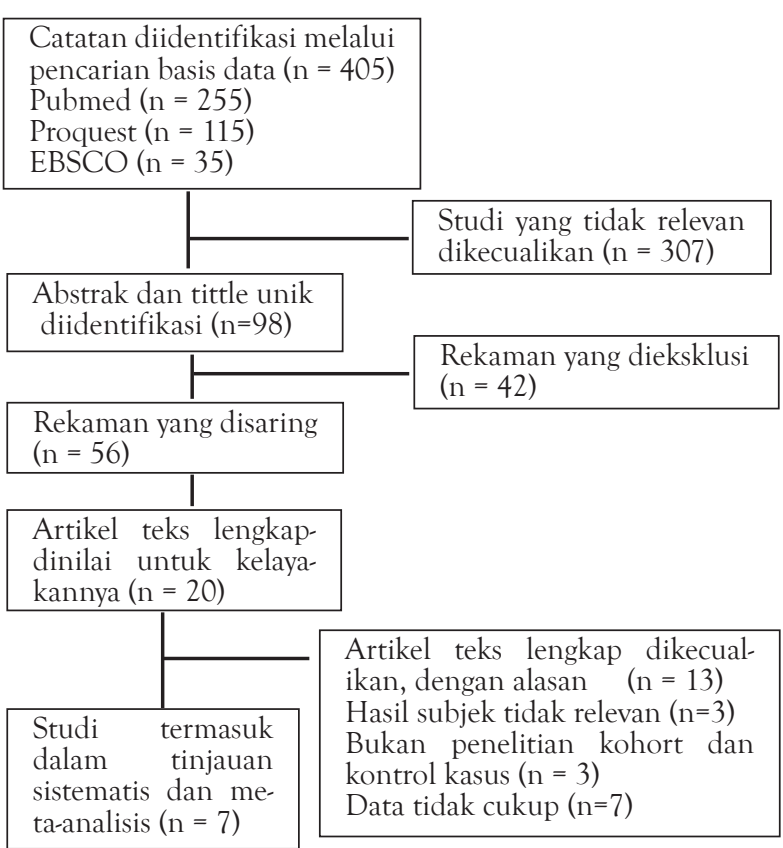




\section{Hasil}

Penelitian ini mendapatkan 7 artikel penelitian yang relevan untuk dilakukan studi meta analisis (Gambar 1 dan Tabel 1).

Gambar 1 dan tabel 1 diketahui terdapat 7 artikel penelitian yang dilakukan meta analisis dimana kesemua artikel merupakan penelitian dengan studi kohort.

Meta analisis pengaruh konsumsi serat dengan pengurangan risiko kanker kolon di negara barat (Gambar 2).

Gambar 2 diketahui konsumsi serat dengan risiko kanker kolorektal di negara barat (RR $=0,83[95 \%$ CI 0,75-0,93]). Hasil penelitian ini menyimpulkan konsumsi serat mengurangi resiko kanker kolorektal di negara barat.

\section{Pembahasan}

Hasil penelitian diketahui konsumsi serat dapat mengurangi risiko kanker kolorektal di negara barat $(\mathrm{RR}=0,83$ [95\% CI 0,75-0,93]). Beberapa penelitian telah menyatakan peran serat untuk mengurangi kanker kolorektal. Asupan serat yang tinggi, terutama dari sereal atau biji-bijian dan buah-buahan, dikaitkan dengan penurunan risiko insiden kanker kolorektal. ${ }^{(8,12,20)}$ Studi prospektif dalam uji skrining berbasis populasi menunjukkan bahwa individu yang mengonsumsi asupan serat makanan tertinggi telah mengurangi risiko insiden kanker kolorektal. ${ }^{(11)}$

Sumber serat dari buah, sayuran, kacang-kacangan, sereal dan biji-bijian. Asupan karotenoid, sayuran hijau muda, sayuran kuning-oranye, brokoli, jagung, wortel, pisang, bawang putih, dan kacang polong (termasuk produk kedelai) berperan dalam terjadinya kanker kolorektal. Serat dari sayuran berperan besar dalam melindungi riisko kanker kolorektal. ${ }^{(21)}$

Mekanisme serat dari makanan dapat mengurangi risiko kanker kolorektal dijelaskan melalui adanya cairan pelumas pada saat buang air besar, dan mengurangi waktu transit, sehingga mengurangi kontak antara karsinogen dan lapisan kolon dan rektum. Selain itu, terdapatnya fermentasi bakteri dari serat dan memproduksi asam lemak rantai pendek, yang mungkin memiliki efek perlindungan terhadap kanker kolorektal. Buah, sayuran, kacang-kacangan, sereal dan serat biji-bijian juga dapat melindungi terhadap kanker kolorektal, termasuk antioksidan, vitamin, mineral, fitat, asam fenolik, lignan, dan fitoestrogen. (22-24)

Penelitian ini mengkonfirmasi konsumsi serat mengurangi risiko pasien kanker kolorektal di negara-negara barat. Hasil penelitian ini merekomendasikan perlunya menjaga konsumsi serat.

Tabel 1. Telaah sistematis pengaruh konsumsi serat dengan pengurangan risiko kanker kolon di negara barat

\begin{tabular}{|c|c|c|c|c|c|c|c|c|}
\hline Penulis, Tahun & Wilayah & $\begin{array}{l}\text { Tipe } \\
\text { Studi }\end{array}$ & $\begin{array}{l}\text { Karak- } \\
\text { teristik }\end{array}$ & $\begin{array}{l}\text { Lama } \\
\text { Studi }\end{array}$ & $\begin{array}{l}\text { Jumlah } \\
\text { Sampel }\end{array}$ & Asupan Serat & Penilaian Diet & Ukuran efek \\
\hline $\begin{array}{l}\text { Bingham et } \\
\text { al (a) }\end{array}$ & Eropa & $\begin{array}{l}\text { Ko- } \\
\text { hort }\end{array}$ & $\begin{array}{l}25-70 \\
\text { tahun }\end{array}$ & $\begin{array}{c}6 \\
\text { tahun }\end{array}$ & 434.209 & $\begin{array}{c}12.71 \text { vs } 26.06 \\
\mathrm{gr} / \mathrm{hari}\end{array}$ & $\begin{array}{l}\text { Kuesioner diet khu- } \\
\text { sus negara }\end{array}$ & $\begin{array}{c}\text { HR }(95 \% \text { CI): } \\
0.72(0.54-0.97)\end{array}$ \\
\hline $\begin{array}{l}\text { Bingham et al } \\
\text { (b) }\end{array}$ & Eropa & $\begin{array}{l}\text { Ko- } \\
\text { hort }\end{array}$ & $\begin{array}{l}25-70 \\
\text { tahun }\end{array}$ & $\begin{array}{l}6.2 \\
\text { tahun }\end{array}$ & 519.978 & $\begin{array}{c}17.05 \text { vs } 23.45 \\
\mathrm{gr} / \mathrm{hari}\end{array}$ & $\begin{array}{l}\text { Kuesioner diet yang } \\
\text { dikelola sendiri }\end{array}$ & $\begin{array}{c}\text { HR }(95 \% \mathrm{CI}): \\
0.74(0.58-0.93)\end{array}$ \\
\hline Schatzkin et al & USA & $\begin{array}{l}\text { Ko- } \\
\text { hort }\end{array}$ & $\begin{array}{l}50-71 \\
\text { tahun }\end{array}$ & $\begin{array}{c}5 \\
\text { tahun }\end{array}$ & 489.511 & $\begin{array}{c}6.6 \text { vs } 15.9 \text { gr/ } \\
\text { hari }\end{array}$ & $\begin{array}{l}\text { Kuesioner frekuensi } \\
\text { makanan }\end{array}$ & $\begin{array}{c}\text { RR (95\%CI): } 0.96 \\
\quad(0.80-1.15)\end{array}$ \\
\hline Vulcan et al & Swedia & $\begin{array}{l}\text { Ko- } \\
\text { hort }\end{array}$ & $\begin{array}{l}66-93 \\
\text { tahun }\end{array}$ & $\begin{array}{l}15.4 \\
\text { tahun }\end{array}$ & 27.931 & $\begin{array}{l}0.1-7 \text { vs } 2.7-8 \\
\mathrm{gr} / \mathrm{mega} \mathrm{joule}\end{array}$ & $\begin{array}{l}\text { Kuesioner frekuensi } \\
\text { makanan }\end{array}$ & $\begin{array}{c}\text { HR }(95 \% \text { CI): } 0.68 \\
\quad(0.48-0.96)\end{array}$ \\
\hline Terry et al & Swedia & $\begin{array}{l}\text { Ko- } \\
\text { hort }\end{array}$ & $\begin{array}{l}40-74 \\
\text { tahun }\end{array}$ & $\begin{array}{l}9.6 \\
\text { tahun }\end{array}$ & 61.463 & $\begin{array}{c}12.3 \text { vs } 21.8 \mathrm{gr} / \\
\text { hari }\end{array}$ & $\begin{array}{l}\text { Kuesioner frekuesni } \\
\text { makanan }\end{array}$ & $\begin{array}{c}\text { RR (95\%CI): } 0.84 \\
(0.59-1.20)\end{array}$ \\
\hline $\begin{array}{l}\text { McCullough } \\
\text { et al }\end{array}$ & USA & $\begin{array}{l}\text { Ko- } \\
\text { hort }\end{array}$ & $\begin{array}{l}40-74 \\
\text { tahun }\end{array}$ & $\begin{array}{c}5 \\
\text { tahun }\end{array}$ & 70.554 & $<8$ vs $31 \mathrm{gr} / \mathrm{hari}$ & $\begin{array}{l}\text { Kuesioner frekuensi } \\
\text { makanan }\end{array}$ & $\begin{array}{c}\text { RR }(95 \% \mathrm{CI}): 1.09 \\
\quad(0.58-2.05)\end{array}$ \\
\hline Hansen et al & $\begin{array}{l}\text { Skandi- } \\
\text { navia }\end{array}$ & $\begin{array}{l}\text { Ko- } \\
\text { hort }\end{array}$ & $\begin{array}{l}30-64 \\
\text { tahun }\end{array}$ & $\begin{array}{l}11.3 \\
\text { tahun }\end{array}$ & 69.229 & $\begin{array}{c}15.4-19.6 \text { vs } 24.5 \\
\mathrm{gr} / \mathrm{hari}\end{array}$ & $\begin{array}{l}\text { Kuesioner frekuensi } \\
\text { makanan }\end{array}$ & $\begin{array}{c}\text { RR }(95 \% \mathrm{CI}): 0.87 \\
(0.65-1.18)\end{array}$ \\
\hline
\end{tabular}

Singkatan: HR, Hazard Ratio; RR, Risk Relative 
Gambar 2. Meta analisis pengaruh konsumsi serat dengan pengurangan risiko kanker kolon di negara barat

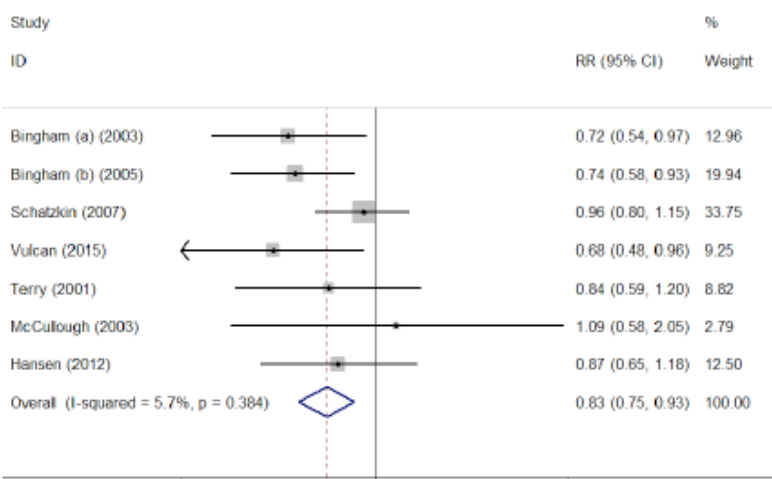

Serat makanan bisa menjadi tindakan yang efektif untuk pencegahan kolorektal. Studi ini menunjukkan perlunya pendidikan dan konseling kesehatan tentang kebiasaan makan dan pentingnya mengkonsumsi makanan dengan kandungan serat tinggi.

\section{Kesimpulan}

Penelitian ini menyimpulkan konsumsi serat dapat mengurangi risiko kanker kolorektal di negara barat.

\section{Ucapan Terima Kasih}

Peneliti mengucapkan terima kasih kepada Ricvan Dana Nindrea, MPH yang telah membantu dalam proses pengumpulan, pengolahan dan analisis data penelitian.

\section{Daftar Pustaka}

1. Wolpin BM, Mayer RJ. Systemic treatment of colorectal cancer. Gastroenterology. 2008; 134: 1296-310.

2. Moghimi-Dehkordi B, Safaee A. An overview of colorectal cancer survival rates and prognosis in Asia. World J Gastrointest Oncol. 2012; 4: 71-5.

3. Kokki I, Papana A, Campbell H, Theodoratou E. Estimating the incidence of colorectal cancer in South East Asia. Croat Medical Journal. 2003; 54: 532-40.

4. Giovanucci E. Modifiable risk factors for colon cancer. Gastroenterol Clin North Am. 2002; 31: 925-43
5. Nindrea RD, Aryandono T, Lazuardi L. Breast cancer risk from modifiable and non-modifiable risk factors among women in Southeast Asia: a meta-analysis. Asian Pac J Cancer Prev. 2017; 18: 3201-6.

6. Vargas AJ, Thompson PA. Diet and nutrient factors in colorectal cancer risk. Nutr Clin Pract. 2012; 27: 613-23.

7. Murphy N, Norat T, Ferrari P, Jenab M, Bueono-de-Mesquita, Skeie G, et al. Dietary fibre intake and risks of cancers of the colon and rectum in the European Prospective Investigation into Cancer and Nutrition (EPIC). Plos One. 2012; 7: 1-10.

8. Song Y, Liu M, Yang FG, Cui LH, Lu XY, Chen C. Dietary fibre and the risk of colorectal cancer: a case-control study. Asian Pac J Cancer Prev. 2015; 16: 3747-52.

9. Zhong X, Fang YJ, Pan ZZ, Lu MS, Zheng MC, Chen YM, Zhang CX. Dietary fiber and fiber fraction intakes and colorectal cancer risk in Chinese adults. Nutr Cancer. 2014; 66: 35161.

10. Aune D, Chan DSM, Lau R, Greenwoon DC, Kampman E, Norat T. Dietary fibre, whole grains, and risk of colorectal cancer: systematic review and dose-response meta-analysis of prospective studies. BMJ. 2011; 343: d6617.

11. Kunzmann AT, Coleman HG, Huang WY, Kitahara CM, Cantwell MM, Berndt SI. Dietary fiber intake and risk of colorectal cancer and incident and recurrent adenoma in the Prostate, Lung, Colorectal, and Ovarian Cancer Screening Trial. Am J Clin Nutr. 2015; 102, 881-90.

12. Park Y, Hunter DJ, Spiegelman D, Bergkvist L, Berrino F, van den Brandt PA, et al. Dietary fiber intake and risk of colorectal cancer: a pooled analysis of prospective cohort studies. JAMA. 2005; 294: 2849-57.

13. Bingham SA, Day NE, Luben R, Ferrari P, Slimani N, Norat T, et al. Dietary fibre in food and protection against colorectal cancer in the European Prospective Investigation into Cancer and Nutrition (EPIC): an observational study. Lancet. 2003; 361:1496-1501.

14. Bingham SA, Norat T, Moskal A, Ferrari P, 
Slimani N, Clavel-Chapelon F, et al. Is the association with fiber from foods in colorectal cancer confounded by folate intake? Cancer Epidemiol Biomarkers Prevent. 2005; 14:1552-56.

15. Schatzkin A, Mouw T, Park Y, Subar AF, Kipnis V, Hollenbeck A, et al. Dietary fiber and whole-grain consumption in relation to colorectal cancer in the NIH-AARP Diet and Health Study. Am J Clin Nutr. 2007; 85:1353-60.

16. Vulcan A, Brandstedt J, Manjer J, Jirstrom K, Ohlsson B, Ericson U. Fibre intake and incident colorectal cancer depending on fibre source, sex, tumour location and Tumour, Node, Metastasis stage. Br J Nutr. 2015; 114:959-69.

17. Terry P, Giovannucci E, Michels KB, Bergkvist L, Hansen H, Holmberg L, Wolk A. Fruit, vegetables, dietary fiber, and risk of colorectal cancer. J Natl Cancer Inst. 2001; 93: 525-33.

18. McCullough ML, Robertson AS, Chao A, Jacobs EJ, Stampfer MJ, Jacobs DR, et al. A prospective study of whole grains, fruits, vegetables and colon cancer risk. Cancer Causes Control. 2003; 14:959-70.

19. Hansen L, Skeie G, Landberg R, Lund E, Palmqvist R, Johansson I, et al. Intake of dietary fiber, especially from cereal foods, is associated with lower incidence of colon cancer in the HELGA cohort. Int J Cancer. 2012; 131:469-78.

20. Ben W, Sun Y, Chai R, Qian A, Xu B, Yuan Y. Dietary fiber intake reduces risk for colorectal adenoma: a meta-analysis. Gastroenterology. 2014; 146: 689-99.

21. Le Marchand L, Hankin JH, Wilkens LR, Kolonel LN, Englyst HN, Lyu LC. Dietary fiber and colorectal cancer risk. Epidemiology. 1997; 8: 658-65.

22. Slavin JL. Mechanisms for the impact of whole grain foods on cancer risk. J Am Coll Nutr. 2000; 19: S300-7.

23. Cotterchio M, Boucher BA, Manno M, Gallinger S, Okey A, Harper P. Dietary phytoestrogen intake is associated with reduced colorectal cancer risk. J Nutr. 2006; 136: 3046-53.
24. Nindrea RD, Aryandono T, Lazuardi L, Dwiprahasto I. Protective effect of omega-3 fatty acids in fish consumption against breast cancer in Asian patients: a meta-analysis. Asian Pac J Cancer Prev. 2018; 19: 2643-9. 